\title{
A CONSTRUÇÃO DE UM CONCEITO DE SUSTENTABILIDADE SOLIDÁRIA CONTRIBUIÇÕES TEÓRICAS PARA O ALCANCE DO SOCIOAMBIENTALISMO
}

\section{THE CONSTRUCTION OF A SOLIDARITY SUSTAINABILITY CONCEPT THEORETICAL CONTRIBUTIONS TO THE REACH OF SOCIO- ENVIRONMENTALISM}

\author{
Heloise Siqueira Garcia ${ }^{1}$ \\ Denise Schmitt Siqueira Garcia ${ }^{2}$
}

\section{RESUMO}

O artigo tem como objetivo geral traçar considerações acerca do conceito de sustentabilidade tendo como aparato sua íntima ligação com a solidariedade, de modo que os estudos traçados apresentem-se como contribuições teóricas para o socioambientalismo. Nesse diapasão foram elencados os seguintes objetivos específicos: analisar os principais aspectos da Sustentabilidade, dando enfoque à dimensão social; estudar a Solidariedade em seus aspectos históricos e conceituais; e compreender a íntima correlação entre ambas as categorias. $\mathrm{Na}$ metodologia foi adotado o método indutivo, tendo sido acionadas as técnicas do referente, da categoria, dos conceitos operacionais, da pesquisa bibliográfica e do fichamento.

Palavras-chave: Sustentabilidade; Solidariedade; Socioambientalismo.

\begin{abstract}
The article has as general objective to draw up considerations about the concept of sustainability having as its apparatus its intimate connection with solidarity, so that the studies traced are presented as theoretical contributions to socio-environmentalism. In this context, the following specific objectives were listed: analyze the main aspects of Sustainability, focusing on the social dimension; to study Solidarity in its historical and conceptual aspects; and to understand the close correlation between both categories. In the methodology was adopted the inductive method, having been applied the techniques of the referent, category, operational concepts, bibliographical research and file.
\end{abstract}

Keywords: Sustainability; Solidarity; Socio-Environmentalism. INTRODUÇÃO

\footnotetext{
${ }^{1}$ Doutoranda em Ciência Jurídica pela Universidade do Vale do Itajaí - UNIVALI, Santa Catarina, (Brasil). Mestre em Ciência Jurídica pelo PPCJ - UNIVALI. Mestre em Derecho Ambiental y de la Sostenibilidad pela Universidad de Alicante, (Espanha). Advogada. Email: helo sg@ hotmail.com

2 Doutora em Direito Ambiental e Sustentabilidade pela Universidad de Alicante - UA, (Espanha). Professora do Programa de Pós-Graduação Stricto Sensu em Ciência Jurídica da UNIVALI - PPCJ. Mestre em Direito Ambiental pela Universidade de Alicante - UA, (Espanha). Advogada. E-mail: denisegarcia@univali.br
} 
O artigo tem como tema principal a busca de uma análise dos ideais e objetivos da Sustentabilidade e da Solidariedade, estabelecendo a sua correlação inata, estabelecendo-se a partir de tal análise contribuições teóricas para o socioambientalismo.

Por tudo isto, este artigo terá como objetivo geral traçar considerações acerca do conceito de sustentabilidade tendo como aparato sua íntima ligação com a solidariedade, de modo que os estudos traçados apresentem-se como contribuições teóricas para o socioambientalismo. E como objetivos específicos analisar os principais aspectos da Sustentabilidade, dando enfoque à dimensão social; estudar a Solidariedade em seus aspectos históricos e conceituais; e compreender a íntima correlação entre ambas as categorias.

Portanto, como problemas centrais serão enfocados os seguintes questionamentos: $\mathrm{O}$ que é Sustentabilidade e quais suas principais dimensões doutrinariamente tratadas? Quais as divergências conceituais da Solidariedade e qual a base da sua construção teórica na histórica? Qual a correlação entre os objetivos da Sustentabilidade e da Solidariedade?

Para tanto, o artigo foi dividido em duas partes: A Sustentabilidade e seu Caráter Social; A Solidariedade em seu aspecto mais amplo.

Com relação à metodologia adotada ressalta-se que a opção das autoras deu-se pelo método indutivo, tendo sido acionadas as técnicas do referente ${ }^{3}$, da categoria ${ }^{4}$, dos conceitos operacionais $^{5}$, da pesquisa bibliográfica ${ }^{6}$ e do fichamento ${ }^{7}$.

\section{A SUSTENTABILIDADE E SEU CARÁTER SOCIAL}

Pelos estudos de Bosselmann (2015, 28-45), tem-se a constatação que a história do Direito Ambiental não começou nos anos 60, mas é tão antiga quanto a história jurídica europeia, sendo que a ideia de sustentabilidade e o seu conceito influenciaram o desenvolvimento de diversas leis de países europeus.

\footnotetext{
3 "explicitação prévia do motivo, objetivo e produto desejado, delimitado o alcance temático e de abordagem para uma atividade intelectual, especialmente para uma pesquisa". (PASOLD, 2007, p. 241).

4 "palavra ou expressão estratégica à elaboração e/ou expressão de uma idéia". (PASOLD, 2007, p. 229).

5 "definição estabelecida ou proposta para uma palavra ou expressão, com o propósito de que tal definição seja aceita para os efeitos das idéias expostas". (PASOLD, 2007, p. 229).

6 "Técnica de investigação em livros, repertórios jurisprudenciais e coletâneas legais". (PASOLD, 2007, p. 240).

7 "Técnica que tem como principal utilidade otimizar a leitura na Pesquisa Científica, mediante a reunião de elementos selecionados pelo Pesquisador que registra e/ou resume e/ou reflete e/ou analisa de maneira sucinta, uma Obra, um Ensaio, uma Tese ou Dissertação, um Artigo ou uma aula, segundo Referente previamente estabelecido". (PASOLD, 2007, p. 233).
} 
Segundo relatos do autor, os conceitos de sustentabilidade surgiram cerca de 600 anos antes do século XX, momento em que a Europa continental sofreu uma grave crise ecológica decorrente do desenvolvimento agrícola e da utilização da madeira ocorridos entre 1300 e 1350, que atingiram nível tal que quase levou ao desmatamento completo da Europa. Em resposta a essa crise principados e cidades locais começaram a tomar medidas de reflorestamento em larga escala, promulgando leis fundadas na sustentabilidade, estabelecendo-se a ideia de que não se deveria desmatar madeira além do que pudesse crescer novamente e plantar novas árvores para que as gerações futuras fossem beneficiadas, dava-se vazão ao manejo florestal sustentável. (BOSSELMANN, 2015, p. 30-31)

Tais leis e medidas se mostraram eficazes até 1800, quando a Europa viu-se diante de outra crise ambiental e alimentar. De forma simultânea, a civilização agrícola tradicional passou a dar lugar à moderna civilização industrial, vivenciava-se a Revolução Industrial, que levou a uma profunda transformação da terra e do uso dos recursos naturais e tornou-se catalisadora da economia moderna. (BOSSELMANN, 2015, p. 33-34)

Toda essa mudança acabou por refletir, por óbvio, no Direito, que cada vez mais deixou para trás seu caráter orientado pela sustentabilidade local e pública para adotar critérios de "livre iniciativa privada", o que levou, no início do século XIX, a praticamente o desaparecimento dos direitos públicos ambientais. "O sistema emergente de direito privado e os direitos de propriedade absoluta ignoraram, em grande parte, a proteção ambiental, para não mencionar a sustentabilidade.” (BOSSELMANN, 2015, p. 33)

Apesar de todas essas vivências históricas, foi somente a partir da década de 60 que tiveram início as discussões a nível mundial que temas que mencionavam expressamente o termo "Direito Ambiental”, o que, na concepção de Real Ferrer (2011; 2012), ensejou a “primeira onda" numa visão de progresso cronológico e impulsos políticos. Apresentando seu ápice na primeira conferência mundial sobre meio ambiente ocorrida em 1972 em Estocolmo, a qual permitiu a proliferação da legislação ambiental e a sua constitucionalização em diversos países.

A "segunda onda" se desenvolveu com a segunda conferência mundial sobre meio ambiente ocorrida em 1992, sediada na cidade do Rio de Janeiro, onde começou a haver articulações de movimentos com surgimento de organizações não governamentais (ONG's) e o aumento do número de novos agentes sociais implicados com a proteção ambiental, ademais, todos os países participantes passaram a se dotar de abundante e moderna legislação 
ambiental, dando lugar a uma onda de normas e possibilitando o surgimento do que Real Ferrer chamou da "geração da fotocópia" 8 . O grande destaque que se pode dar foram as discussões surgidas acerca das dimensões da sustentabilidade.

A "terceira onda" surgiu com a Conferência Mundial sobre o Meio Ambiente de 2002, ocorrida em Johannesburg, também conhecida como Rio +10 , essa sim com um enfoque muito forte no desenvolvimento sustentável. Sendo que foi nessa conferência que finalmente houve a integração das três dimensões da sustentabilidade mais doutrinariamente consideradas: a ambiental, a social e a econômica.

Entretanto, apesar de se reconhecer os avanços que propôs a Conferência, a sensação foi de fracasso e indiferença, pois se acordaram diversas metas e medidas, porém não se instauraram meios efetivos para controlar sua implementação e eficácia, não se dando nenhum passo à institucionalização de uma eficaz governança ambiental planetária, sentimento este que se estendeu até a Conferência Mundial sobre o Meio Ambiente ocorrida no ano de 2012, novamente na cidade do Rio de Janeiro, conhecida como Rio +20, tratada como a "quarta onda" (REAL FERRER, 2012, p. 318).

A referida Conferência, última ocorrida, teve como objetivo reforçar o compromisso político dos Estados em relação ao desenvolvimento sustentável, identificando os progressos nos compromissos já firmados no âmbito da ONU, assim como desafios emergentes ainda não trabalhados. (VIEIRA, 2012, p. 50) Seu foco, conforme explana Vieira (2012, p. 50), ateve-se a dois temas centrais: "[...] a transição para a economia verde e a governança global do desenvolvimento sustentável.”

Destacando Cruz e Bodnar (2012, p. 169) que foram basicamente três as propostas da conferência:

A primeira foi a de criar um novo organismo na ONU específico para a área ambiental. A segunda foi de dar ao PNUMA (Programa das Nações Unidas Para o Meio Ambiente) um novo status, igualando-o a organismos como a OMC (Organização Mundial do Comércio). A terceira proposta foi a de se promover a elevação do poder da Comissão de Desenvolvimento Sustentável da ONU.

Comenta Milaré (2013, p. 1572) que o que aconteceu durante a Rio +20 foi que esta enfrentou a frieza do cenário internacional, sendo que o principal elemento da sua preparação foi o ceticismo da Cúpula dos Governos e, também, da Cúpula dos Povos. O Brasil era mais

\footnotetext{
${ }^{8} \mathrm{O}$ que aconteceu foi a grande reprodução das normas umas às outras, sem se considerar qualquer realidade social, econômica, jurídica e ambiental sobre que se projetavam. Sobre o tema ver: REAL FERRER, 2002.
} 
uma vez o anfitrião da grande conferência mundial, mas ainda possuía a condição de “emergente”, deixando visíveis as dificuldades internas na preparação da Assembleia.

Desse modo, assim como a penúltima Conferência, a sensação obtida após o término desta foi de fracasso em termo de avanços visíveis.

Nos dizeres de Garcia (2012, p. 389), o termo sustentabilidade traz diversas conotações e "[...] decorre do conceito de sustentação, o qual, por sua vez, é aparentado à manutenção, conservação, permanência, continuidade e assim por diante."

Freitas (2012, p. 41) conceitua o Princípio da Sustentabilidade como sendo um

[...] princípio constitucional que determina, com eficácia direta e imediata, a responsabilidade do Estado e da sociedade pela concretização direta e imediata, a responsabilidade do Estado e da sociedade pela concretização solidária do desenvolvimento material e imaterial, socialmente inclusivo, durável e equânime, ambientalmente limpo, inovador, ético e eficiente, no intuito de assegurar, preferencialmente de modo preventivo e precavido, no presente e no futuro, o direito ao bem-estar.

Resumindo, o mesmo autor mais adiante em sua obra, trata que a sustentabilidade suportaria, então, 10 elementos básicos: 1. É princípio constitucional de aplicação direta e imediata; 2. Reclama por resultados justos e não apenas efeitos jurídicos, ou seja, reclama por eficácia; 3. Em ligação à eficácia demanda eficiência; 4. Tem como objetivo tornar o ambiente limpo; 5. Pressupõe probidade nas relações públicas e privadas; 6. 7. 8. Implica prevenção, precaução e solidariedade intergeracional; 9. Implica no reconhecimento da responsabilidade solidária do Estado e da sociedade; e 10. Todos os demais elementos devem convergir para ideia de garantir um bem-estar duradouro e multidimensional. (FREITAS, 2012, p. 50)

Correlaciona-se por este viés, também, os ditames de Martín Mateo (1998, p. 41), que tendo por base o Princípio da Sustentabilidade, considera que não se trata de instaurar uma espécie de utopia, senão bases pragmáticas, que se farão compatíveis com o desenvolvimento econômico necessário para que nossos congêneres e seus descendentes possam viver dignamente com o respeito de um entorno biofísico adequado.

Deve-se ainda ter em mente que, na realidade, a sustentabilidade é uma dimensão ética, trata de uma questão existencial, pois é algo que busca garantir a vida, não estando simplesmente relacionada à natureza, mas a toda uma relação entre indivíduo e todo o ambiente a sua volta. "Há uma relação complementar entre ambos. Aperfeiçoando o ambiente o homem aperfeiçoa a si mesmo.” (SOARES; CRUZ, 2012, p. 412) 
Sendo nesse sentido que também comenta Real Ferrer (2013, p. 13), afirmando que a sustentabilidade comporta uma noção positiva e altamente proativa, que supõe a introdução das mudanças necessárias para que a sociedade planetária, constituída pela humanidade, seja capaz de se perpetuar indefinidamente no tempo.

Dito isto, deve-se considerar o caráter pluridimensional da Sustentabilidade, salientando-se a divergência presente na doutrina quanto à quantidade de dimensões que suportam a sustentabilidade, destacando-se, contudo, que majoritariamente considera-se a existência de três dimensões, chamadas de tripé da Sustentabilidade, que seriam: a dimensão ambiental, a econômica e a social.

Pela doutrina tradicional a sustentabilidade é tratada sob o viés destas três dimensões, todas integralmente correlatas e dependentes para a construção real da sustentabilidade.

Freitas (2012) trabalha com a ideia de cinco dimensões, além das três tradicionais ainda existiriam a ética ${ }^{9}$ e a jurídico-política ${ }^{10}$. Todas as cinco, em conjunto, tornam-se altamente correlatas e possibilitam a construção real da Sustentabilidade.

Ainda salienta-se mais uma dimensão que aos poucos a doutrina está passando a aceitar a existência, chamada por Cruz, Bodnar e Real Ferrer de dimensão tecnológica, a qual surge num contexto de evolução do homem ante os avanços da globalização, conforme destacam:

A sustentabilidade foi inicialmente construída a partir de uma tríplice dimensão: ambiental, social e econômica. $\mathrm{Na}$ atual sociedade do conhecimento é imprescindível que também seja adicionada a dimensão tecnológica, pois é a inteligência humana individual e coletiva acumulada e multiplicada que poderá garantir um futuro sustentável. Na perspectiva jurídica todas estas dimensões apresentam identificação com a base de vários direitos humanos e fundamentais (meio ambiente, desenvolvimento, direitos prestacionais sociais, dentre outros), cada qual com as suas peculiaridades e riscos. (CRUZ; BODNAR, 2012, p. 112)

Tal dimensão, conforme comenta Real Ferrer (2012, p. 319), é a que marcará as ações que poderemos colocar em marcha para corrigir, se chegarmos a tempo, o rumo atual marcado pela catástrofe. Sem contar que a técnica também define e já definiu nossos modelos

\footnotetext{
${ }^{9}$ A dimensão ética traz a ideia de que todos os seres possuem uma ligação intersubjetiva e natural, da qual segue a concepção da solidariedade como dever universalizável. A cooperação surgiria, então, como um dever evolutivo da espécie, favorável à continuidade da vida no sistema ambiental, sua busca primordial seria o da produção do bem-estar duradouro, com o reconhecimento da dignidade intrínseca de todos os seres vivos, acima, assim, do antropocentrismo estrito, criando uma ética universal concretizável.

${ }^{10}$ A dimensão jurídico-política estabelece que a sustentabilidade determina, independentemente de regulamentação, a tutela jurídica do direito ao futuro, apresentando-se como dever constitucional. A sustentabilidade é vista como princípio jurídico constitucional, imediata e diretamente vinculante, que altera a visão global do Direito, para o qual todos os esforços devem convergir, determinando a eficácia dos direitos fundamentais de todas as dimensões, fazendo com que seja tido como desproporcional e antijurídica toda e qualquer omissão causadora de injustos danos intra e intergeracionais.
} 
sociais, como a roda, as técnicas de navegação, a máquina a vapor, a eletricidade, o automóvel e a televisão, e nesse sentido, a internet, as nanotecnologias e o que se está por chegar também definirá.

Em artigo recente, Cruz e Real Ferrer (2015) trabalham com os fundamentos da premissa tecnológica na sustentabilidade em todas as suas dimensões, destacando que na análise das dimensões clássicas da sustentabilidade o fator tecnológico não é considerado, apesar de ser fundamental, tanto para alcançar o sucesso em cada uma das áreas como para garantir a própria viabilidade da Sustentabilidade.

Feito este adendo, destacam-se algumas das características principais de cada uma das dimensões tradicionalmente consideradas pela doutrina, destacando-se que ao final deste item o foco se dará no âmbito da dimensão social, considerando os fundamentos do presente estudo.

A dimensão ambiental do Princípio da Sustentabilidade diz respeito à importância da proteção do meio ambiente e do Direito Ambiental, tendo como finalidade precípua garantir a sobrevivência do planeta através da preservação e melhora dos elementos físicos e químicos que a fazem possível, considerando sempre o alcance da melhor qualidade de vida do homem na terra. (GARCIA; GARCIA, 2014, p. 44)

Ela prevê, basicamente, a consideração do direito das gerações atuais e futuras ao ambiente limpo em todos os seus aspectos. Nesse diapasão, essa dimensão trata de abarcar, principalmente, as ideias de que não poderá haver qualidade de vida e longevidade digna em um ambiente degradado ou no limite, não se podendo ter, quiçá, a manutenção da vida humana, do que resulta o pensamento de que ou se protege a qualidade ambiental ou não se terá futuro para a espécie humana.

A dimensão econômica foca no desenvolvimento da economia com a finalidade de gerar melhor qualidade de vida às pessoas. Ele passou a ser considerada no contexto da sustentabilidade por dois motivos: 1. Não haveria a possibilidade de retroceder nas conquistas econômicas de desenvolvimento alcançadas pela sociedade mundial; e 2. O desenvolvimento econômico estaria interligado com a dimensão social do Princípio da Sustentabilidade, pois ele é necessário para a diminuição da pobreza alarmante. (GARCIA; GARCIA, 2014, p. 44)

Ela evoca o sopesamento entre a eficiência e a equidade, o que leva ao consequente equilíbrio dos benefícios e custos diretos e indiretos (externalidades) dos empreendimentos públicos e privados, estando tudo isso intimamente ligado à ideia de medição das 
consequências a longo prazo. Desse modo, a sustentabilidade geraria uma nova economia, visada à reformulação de categorias e comportamentos que busquem o planejamento de longo prazo, a ultrapassagem do culto excessivo dos bens posicionais e um sistema competente de incentivos. (FREITAS, 2012, p. 65-67)

A dimensão social consiste no aspecto social relacionado às qualidades dos seres humanos, sendo também conhecida como capital humano. Ela está baseada num processo de melhoria na qualidade de vida da sociedade através da redução das discrepâncias entre a opulência e a miséria com o nivelamento do padrão de renda, o acesso à educação, à moradia, à alimentação. Estando, então, intimamente ligada à garantia dos Direitos Sociais, previstos no artigo $6^{\circ}$ da Carta Política Nacional, e da Dignidade da Pessoa Humana, princípio basilar da República Federativa do Brasil. (GARCIA; GARCIA, 2014, p. 44-45)

Basicamente ela compreende o abrigo dos direitos fundamentais sociais, trazendo a ideia de que não se admite um modelo de desenvolvimento excludente e iníquo, lidando, deste modo, com a garantia da equidade intra e intergeracional, com a criação de condições para a potencialização das qualidades humanas através, principalmente, da garantia de educação de qualidade; e com o desenvolvimento do garantismo à dignidade de todos os seres presentes no planeta.

Há que se ponderar que pela visão desta dimensão a proteção ambiental está diretamente relacionada à garantia dos direitos sociais, já que o gozo destes (como, por exemplo, saúde, moradia, alimentação, educação, etc) em patamares desejáveis constitucionalmente estão necessariamente vinculados às condições ambientais favoráveis, como, por exemplo, o acesso a água potável (através de saneamento básico, que também é direito fundamental social integrante do conteúdo mínimo existencial), à alimentação sem contaminação química (por exemplo, de agrotóxicos e poluentes orgânicos persistentes), a moradia em área que não apresente poluição atmosférica, hídrica ou contaminação do solo (como, por exemplo, na cercania de áreas industriais) ou mesmo riscos de desabamento (como ocorre no topo de morros desmatados e margens de rios assoreados). (GARCIA; GARCIA, 2014, p. 57-58)

A efetividade dos serviços de abastecimento de água e de esgotamento sanitário integra, direta ou indiretamente, o âmbito normativo de diversos direitos fundamentais (mas especialmente dos direitos sociais), como o direito à saúde, o direito à habitação decente, o direito ao ambiente, o "emergente" direito à água (essencial à dignidade humana), bem como, em casos mais extremos, também o direito à vida. (FENSTERSEIFER, 2008, p. 75) 
Bedlin e Garcia (2011, p. 429) bem destacam que a dimensão social não poderá ser olvidada, pois embora o ranking dos maiores poluidores seja composto na maioria por países mais desenvolvidos, “[...] o desenvolvimento social deve ser visto como forma de proteção ambiental, e desenvolvimento sustentável, pois a dimensão social interfere diretamente nestes $[\ldots] "$.

A pobreza não está só vinculada aos critérios sociais de insuficiência de garantias mínimas, mas também, consequentemente, a critérios ambientais e econômicos,

Quanto menor a renda, menor o desenvolvimento social, menor será a preocupação com o meio ambiente. Um cidadão que vive em condições mínimas de sobrevivência, não estará preocupado com a proteção ambiental e sim com o sustento de sua família, sendo indiferente para este se suas atividades laborais degradam ou não o meio ambiente. (BEDLIN; GARCIA, 2011, p. 431)

A pobreza e as desigualdades sociais estão intimamente ligadas à dimensão econômica da sustentabilidade, e também à proteção abarcada pelo socioambientalismo, porém há que se ter em mente que critérios de solidariedade serão necessários para mudança de paradigma no pensamento liberal de crescimento, mudança essa essencial para a garantia de um futuro no mínimo sustentável.

A partir da caracterização de cada uma dessas dimensões, deve-se sempre ter em mente que todas elas estão intimamente entrelaçadas de modo a proporcionar a visão da sustentabilidade como princípio-síntese que determina a proteção da própria vida humana na Terra.

Conforme destacam Irving e Oliveira (2012, p. 36), o sentido da sustentabilidade numa discussão deve envolver a interação com o ambiente, a percepção das relações sociais e a própria subjetividade humana.

O que os estudos sobre a sustentabilidade realmente visam estabelecer é o que Carvalho (2014, p. 773) preleciona: "A sustentabilidade anuncia o limite da racionalidade econômica, proclamando os valores da vida, da justiça social e do compromisso com as gerações vindouras, almejando uma racionalidade ambiental."

Todo esse aporte teórico trabalhado corrobora com a ideia central de que o destino da espécie humana, e aqui ressalta-se o contexto global e transnacional desse entendimento, remanesce em suas próprias mãos, sendo, então, o motivo principal para escolher a sustentabilidade antes de tudo como oportunidade de assegurar para todas as gerações o direito fundamental ao futuro. 
Como sequência de estudo, segundo inclusive o proposto na temática principal do artigo, trabalhar-se-á com a Solidariedade, destacando, em especial, seus aspectos históricos e conceituais, sem perder de vista a desvinculação entre os dois temas.

Há que se considerar que as categorias Sustentabilidade e Solidariedade, como bem destaca Armada (2015, p. 171), são obrigatoriamente vinculadas. Temos de aceitar o caráter finito dos recursos naturais e a possibilidade de colocar em risco a continuação da humanidade por seu uso indiscriminado. Tem de se ter em mente a inclusão do outro no processo de proteção, e mais ainda, incluir aqueles que sequer estão aqui, as gerações futuras, aceitando o direito destas também usufruírem dos patrimônios culturais e ambientais.

\section{A SOLIDARIEDADE EM SEU ASPECTO MAIS AMPLO}

Antes de se começar a tratar sobre algumas breves explanações acerca da Solidariedade, é importante o esclarecimento sobre a divergência conceitual doutrinária existente.

Há doutrinadores que tratam da Solidariedade como sendo sinônimo da Fraternidade, como, por exemplo, Fensterseifer (2008, p. 1112) e Sarlet (FENSTERSEIFER; SARLET, 2013), que serão trabalhados a seguir.

Os que separam a Solidariedade e a Fraternidade, como, por exemplo, Brandão e Ildete Silva (2012), os quais estabelecem que a Fraternidade

[...] constitui uma exigência que se revela na relação horizontal com o outro - que faz o homem agir porque se reconhece no outro como um outro de si mesmo; um outro eu que não sou eu, mas, ao mesmo tempo, sou eu integrando a Sociedade - e, sensibilizado, consciente e motivado passa a agir de forma comprometida e responsável em atitude compatível a um membro integrante de uma mesma e única família humana. (BRANDÃO; SILVA, 2012, p. 2398)

Diferindo-se da solidariedade, pois esta traria a ideia de que uma pessoa só é solidária com a outra pois lhe é vantajosa a solidariedade, e não apenas por um pensamento altruísta, que seria a fraternidade na qualidade de “[...] uma norma ou ideia fundamental que irradia novos sentidos com condição de possibilidade de orientar um novo pensamento, um novo paradigma." (BRANDÃO; SILVA, 2012, p. 2398)

E por fim, há doutrinadores, como Real Ferrer (2003, p. 123-179), que defendem ser a solidariedade um gênero, do qual decorrem algumas espécies, onde a ideia principal de 
fraternidade estaria inserida em um deles, como se explanará adiante. Destaca-se que esta é a ideia eleita pela autora para o desenvolvimento do presente trabalho.

A concepção e o estabelecimento do conceito operacional adotado à categoria de pesquisa são essenciais para o desenvolvimento do trabalho, justificando-se o momento inicial deste item. Isso faz importante, inclusive, quando se busca estipular um pouco da evolução da concepção da solidariedade, pois diversos autores tratam de confundir as categorias.

No viés evolutivo da compreensão dos ensinamentos da solidariedade destaca-se o estudo realizado por Peces Barba (1991, p. 15-62) em artigo publicado já na década de 90, onde trabalha com cinco modelos históricos e apresenta considerações pessoais acerca das dimensões da racionalização da solidariedade como valor.

Tendo o referido estudo por critério do escorço histórico da solidariedade ${ }^{11}$, observase que a solidariedade no decorrer da evolução da civilização humana apresentou cinco grandes momentos históricos que lhe estabeleceram alguns modelos de concepção.

O primeiro momento histórico da solidariedade apresenta concepções de utopia, ou o que Peces Barba (1991, p. 19-22) chama de "poesias da solidariedade", nesse momento a categoria é trabalhada como uma utopia, representando o encontro do "espírito geral de fraternidade", que deriva da vida igual em comunidade e da carência da propriedade privada, sendo que neste momento a compreensão era a de que a ausência de propriedade seria a única maneira de concretização da solidariedade. Seriam obras bases deste período "A utopia" de Thomas Morus (2011) e “A cidade do Sol” de Tommaso Campanella (2004).

No segundo momento histórico, o conceito de solidariedade aproxima-se dos critérios da ética ante o "descobrimento" do "Mundo Novo". Peces Barba (1991, p. 22-26) faz sua análise com base no pensamento espanhol a partir do descobrimento da América, momento em que, segundo ele, o pensamento se encontrará com uma responsabilidade histórica. Nesse momento o valor da solidariedade estabelece-se com a raiz cristã católica, o que será encontrado em outros momentos históricos também. A solidariedade apresenta-se como uma ação positiva.

O terceiro momento relaciona-se às origens da sociedade industrial e o impacto da economia na sociedade. O conceito de solidariedade distancia-se da ideia religiosa e aproxima-se de um conceito mais político, havendo uma quebra de paradigma na sua

\footnotetext{
${ }^{11}$ Importante deixar registrado que se o leitor voltar-se à leitura do artigo de Gregório Peces Barba poderá perceber que em diversos momentos do texto o autor confunde-se na tratativa das categorias solidariedade e fraternidade, trantando-as ora como sinônimos, ora como categorias diversas.
} 
concepção, de modo que utiliza-se de instrumentos públicos e mais abertos, considerando a extensão da sua ação desde os pobres aos que, mesmo trabalhando, não tinham cobertas as suas necessidades básicas. (PECES BARBA, 1991, p. 26-35)

Este terceiro momento, vivenciado entre os Séculos XVIII e XIX, teria sido o mais terrível para os ideais solidários, passando por quatro grandes "sub-momentos": o primeiro, caracterizado pela generalização dos direitos fundamentais, pelo protagonismo da classe trabalhadora, pelas origens do Estado Social e pela ofensiva mais forte contra os valores da solidariedade em nome da "Economia Política", quando a solidariedade é vista tão somente como uma resposta ética à pobreza; o segundo, visto como a "solidariedade moderna", marcado pelo surgimento do Iluminismo e pela obra "A riqueza das nações" de Adam Smith (2016), neste submomento imperava o dualismo economia (individualismo) versus solidariedade, a economia desligou-se dos valores morais e levou ao afastamento total da solidariedade, tanto como valor jurídico como política, estava-se diante do Estado mínimo; o terceiro seguiu a ideias da economia individualista a partir da teoria de Thomas Malthus na sua obra "Ensaio sobre o princípio da população" (MALTHUS, 2014), a economia apresentou-se como uma ciência natural e abandonou a filosofia moral e a solidariedade, nem sequer a ideia de caridade para os indigentes (pessoas que não tinham trabalho ou tinham apenas um trabalho de meio período) tem sentido, o único valor considerável é o da riqueza, reverte-se a ideia de ausência da propriedade para consagrar-se a propriedade privada apresentada como direito natural não igualitário; por fim, o quarto submomento apresenta-se como um pequeno ressurgimento da solidariedade após o exagero na consagração da propriedade privada, os principais reacionárias deste período foram os e passaram a criticar a economia, confrontando-se uma relação entre uma dimensão ética, uma dimensão política e uma dimensão jurídica. (PECES BARBA, 191, p. 26-35)

O penúltimo momento histórico é marcado pela passagem do liberalismo social ao socialismo a partir do Século XIX, quando ocorre a cristalização definitiva do valor da solidariedade e sua influência na configuração de fins e funções da sociedade civil e do Estado. Nesse momento histórico havia o processo de generalização dos direitos fundamentais, a luta pelo reconhecimento do sufrágio universal e do direito de associação e consequentemente a incorporação progressiva da classe trabalhadora às instituições políticas do Estado. Apesar de ser difícil limitar as influências de pensamento, pode-se apontar: certa corrente cristã; uma socialização de setores liberais; a liberalização de setores socialistas; o chamado socialismo reformista, democrático ou liberal de origem ética ou utópica; e uma 
ideia anarquista da realidade. É a fraternidade da trilogia revolucionária e enquadrada na nascente do Estado Social de Direito, que impulsionará uma segunda geração de direitos fundamentais. A solidariedade torna-se valor de partida e não de chegada. (PECES BARBA, 191, p. 35-51)

Por fim, o último momento apontado por Peces Barba (1991, p. 51-55) teve seus fundamentos na década de 90. Foi a partir do Século XX que o valor solidariedade como raiz dos serviços sociais aparece perfilhando, matizando e entrelaçando os diversos pontos de vista apresentados como paradigmas parciais do até então vivido, de modo que toda essa análise sistemática e racional do valor solidariedade apresenta-se como uma forma de sair do diacrônico e entrar no sincrônico. O modelo possível de realização atual do valor solidariedade seria o Estado Social, nessa combinação entre os poderes públicos e as instituições da sociedade civil para a satisfação das necessidades básicas.

A questão problemática, já proposta por Peces Barba (1991, p. 51-55) é a de que as condições derivadas da aparição da informática e de outras técnicas que suprem o trabalho humano produziram uma escassez no trabalho que supõe taxas de desemprego em todos os países desenvolvidos, taxas estas que encontram sérias dificuldades em serem reduzidas. Ademais, a tensão entre países desenvolvidos e subdesenvolvidos em diversas vertentes vêm destacando que o valor da solidariedade adquiriu uma dimensão internacional, sobretudo a partir do processo de descolonização que culmina depois da $2^{\text {a }}$ Guerra Mundial, e a tomada de consciência da situação, que nos últimos anos piorou como o problema da dívida externa. Não é só a pobreza dos homens, é a pobreza dos povos, que supõe nessas nações uma pobreza generalizada, salvo reduzidas minorias.

Numa concepção histórica um pouco mais objetiva, destaca Fensterseifer (2008, p. 111) que o princípio da solidariedade teria "renascido como Fênix" das cinzas jurídicas deixadas pela Revolução Francesa para se transformar num novo marco jurídicoconstitucional do Estado Socioambiental de Direito ${ }^{12}$. Esse renascimento teria ocorrido a partir da segunda metade do século XX, no pós Segunda Guerra Mundial, especialmente por causa das Constituições dos Estados nacionais promulgadas ao longo desse período, que

\footnotetext{
${ }^{12}$ Destaca-se que esta é a nomenclatura utilizada pelo referido autor, porém o mesmo já ressalta que existem inúmeros termos para denominar o novo projeto da comunidade estatal, como por exemplo: Estado Pós-social, Estado Constitucional Ecológico, Estado de Direito Ambiental, Estado do Ambiente, Estado Ambiental de Direito, Estado de Bem-Estar Ambiental, entre outros. In: FENSTERSEIFER, 2008, p. 94.
} 
assim como a Constituição Brasileira de 1988, constituíram um marco para a dignidade humana. (FENSTERSEIFER, 2008, p. 112-113)

No Brasil, foi a Constituição da República Federativa do Brasil do ano de 1988 que trouxe o Princípio da Solidariedade como objetivo da República em seu artigo $3^{\circ}$, inciso I ${ }^{13}$, além de trazer consubstanciado no Preâmbulo ${ }^{14}$ da mesma, ao estabelecer que os direitos sociais e individuais, a liberdade, a segurança, o bem-estar, o desenvolvimento, a igualdade e a justiça como valores supremos de uma sociedade fraterna. (FENSTERSEIFER, 2008, p. 113) O que demonstra, também, a confusão que a própria Carta Magna faz entre a Solidariedade e a Fraternidade.

Silva (2008, p. 46), ao fazer comentário contextual ao referido artigo da Carta Magna, destaca realmente a correlação entre ele e as promessas apresentadas no Preâmbulo,

[...] pois "construir uma sociedade livre, justa e solidária" corresponde a formas uma sociedade dotada dos valores supremos dos direitos sociais e individuais, tais a liberdade, a segurança, o bem-estar, o desenvolvimento, a igualdade e a justiça - que é aquela sociedade fraterna, pluralista e sem preconceitos e fundada na harmonia social. (SILVA, 2008, p. 46)

Isso só corrobora as ideias de Kelsen (2005, p. 334) ao estabelecer o povo como um dos "elementos" do Estado segundo a teoria tradicional, entendendo por povo os seres humanos que residem dentro do território do Estado, a sociedade. Uma unidade que representa a esfera pessoal de validade da ordem jurídica nacional.

Compreendidos os aspectos conceituais e históricos principais, necessários para a compreensão da solidariedade, hoje vista como princípio, ou como valor, resume-se nas próximas linhas a sua principal concepção para o presente estudo.

Real Ferrer (2003, p. 123-179) conceitua a solidariedade e o atuar solidário como uma técnica necessária para materializar o materialmente inexistente, mas latente Contrato Social que está na origem a sociedade politicamente organizada dessa comunidade de interesses que é o Estado.

"Un pacto que se renueva periódicamente, diariamente, diría. Pacto que está en la Constitución y en las leyes, y que debe tenerse presente a diario pues es el único capaz de trasmutar la naturaleza de nuestra actividad.” (REAL FERRER, 2003, p. 123-179)

\footnotetext{
${ }^{13}$ Art. $3^{\circ}$ Constituem objetivos fundamentais da República Federativa do Brasil: I - construir uma sociedade livre, justa e solidária [...] in: BRASIL. 1988.

14 "Nós, representantes do povo brasileiro, reunidos em Assembléia Nacional Constituinte para instituir um Estado Democrático, destinado a assegurar o exercício dos direitos sociais e individuais, a liberdade, a segurança, o bem-estar, o desenvolvimento, a igualdade e a justiça como valores supremos de uma sociedade fraterna, pluralista e sem preconceitos, fundada na harmonia social e comprometida, na ordem interna e internacional, com a solução pacífica das controvérsias, promulgamos, sob a proteção de Deus, a seguinte CONSTITUIÇÃO DA REPÚBLICA FEDERATIVA DO BRASIL.” In: BRASIL. 1998.
} 
Martín Mateo (1998, p. 48) explana que a solidariedade deve ser um imperativo não somente ético, mas também prático, imposto pela base internacional da maioria dos sistemas naturais e pela necessidade de limitar, no campo do desenvolvimento sustentável um excessivo uso dos recursos.

Corroborando tal pensamento os estudos de Bodnar (2016, p. 143-171), que destaca o fato de que a solidariedade contempla um substrato ético, pois é valor fundamental para organização e harmonia das relações entre os seres humanos, o entorno e o porvir.

Sarlet e Fensterseifer (2013, p. 56) comentam que ela expressa a necessidade (dever na forma jurídica) fundamental de coexistência do ser humano na sociedade, formatando a teia de relações intersubjetivas e sociais que se traça, no espaço da comunidade estatal.

Considerando, como já comentado, que a ideia defendida no presente artigo é a de que a solidariedade se encaixaria como um gênero, do qual decorreriam algumas espécies, destaca-se o estudo de Real Ferrer, como já comentado, que além de estuda-la desta maneira, ainda a liga a diversos aspectos relativamente ambientais e administrativos.

A partir da divisão do referido autor, destaca-se essencialmente duas das espécies da solidariedade, sendo que as demais apresentadas ligam-se mais diretamente aos ditames do Direito Administrativo, seriam a solidariedade egoísta e a solidariedade altruísta. (REAL FERRER, 2003, p. 123-179)

A solidariedade egoísta traz a ideia de que o indivíduo atua em favor do grupo porque com isso ele tem um benefício duplo: “[...] la mejora del grupo en la que se encuentra y su mejora personal en forma de retornos.” (REAL FERRER, 2003, p. 123-179) Destaca Real Ferrer que essa dimensão da solidariedade, como ele trata, é própria de todos os grupos humanos e é compartilhada, com maior ou menor lucidez, por todos os indivíduos que o compõe. Pode-se dizer que este tipo de solidariedade se liga estritamente com o Estado Liberal e com a ideia de solidariedade pura para àqueles que defendem a divisão entre Solidariedade e Fraternidade.

Já a solidariedade altruísta traz a ideia de que o indivíduo atua na sociedade sem esperar um benefício direto ou indireto, ligando-se estreitamente com o ideal que se busca na implementação de um Estado Democrático de Direito. (REAL FERRER, 2003, p. 123-179) Pode-se dizer que este tipo de solidariedade se assemelharia a ideia trazida de Fraternidade pelos que defendem a divisão entre esta e a Solidariedade. 
Real Ferrer (2003, p. 123-179) salienta que numa sociedade existirá ambos os tipos de solidariedades, mas que a que deveria ser sempre proeminente era a altruísta, como um verdadeiro caráter de solidariedade na busca de um Estado Democrático de Direito.

Peces Barba (1991, p. 55-57) bem reflete que mesmo que a solidariedade tenha um valor religioso, seu posicionamento atual é no âmbito social e político como impulso ético de ações da sociedade e dos poderes públicos para satisfazer necessidades básicas que alcançam formas jurídicas como direitos subjetivos que geram deveres correlativos.

A Solidariedade expressa valores contrários aos da economia clássica e ao liberalismo individualista, que apenas vinculava os indivíduos através de contratos e que tinha uma ideia de Direito com duas funções principais: garantidora e repressora. Hoje a solidariedade expressa valores do homem em comunidade, em relações de integração com os demais homens para realizar objetivos comuns e compartilhados. (PECES BARBA, 1991, p. $55-57)$

Por tais razões seus valores são construídos, inclusive, por vieses de garantida da dignidade da pessoa humana, essa compreendida, a partir dos ditames de Sarlet (2007, p. 383), como:

[...] a qualidade intrínseca e distintiva reconhecida em cada ser humano que o faz merecedor do mesmo respeito e consideração por parte do Estado e da comunidade, implicando, neste sentido, um complexo de direito e deveres fundamentais que assegurem a pessoa tanto contra todo e qualquer ato de cunho degradante e desumano, como venham a lhe garantir as condições existenciais mínimas para uma vida saudável, além de propiciar e promover sua participação ativa e co-responsável nos destinos da própria existência e da vida em comunhão com os demais seres humanos. [itálico no original]

A construção dessa visão solidária está intimamente ligada, inclusive, aos critérios da Civilização Empática discutida por Rifkin (2010), que acaba por demonstrar a existência da empatia global em um mundo interconectado, capaz de salvar a Terra e evitar o fim da civilização.

A empatia, conforme ditames do autor, se expressa como a vontade do observador de tomar parte na experiência de outra pessoa, de compartilhar a sensação dessa experiência. "La empatía es el medio psicológico por el que pasamos a formar parte de la vida de otras personas y compartimos experiencias valiosas." (RIFKIN, 2010, p. 29)

Tudo isso constrói, entre outros ditames, a ideia de criação de uma consciência global solidária que permita a ampliação da visão humana para os problemas que assolam toda a humanidade, problemas estes que da mesma forma repercutem a toda ela de volta, 
como num efeito bumerangue, já pressentido por Beck em sua Sociedade de Risco (2011, p. 27-28).

Ademais, há que se ponderar a correlação da solidariedade com a sustentabilidade, como brevemente exposto acima. Destaca Campello (2016, p. 219) que o próprio conceito de solidariedade ficou aclarado pelo de desenvolvimento sustentável estabelecido em Brudtland ${ }^{15}$ quando destaca a proteção ambiental para as presentes e futuras gerações. Trata-se do caráter intra e intergeracional da sustentabilidade também apontado por Freitas (2012, p. 117).

Outrossim, destaques merecem para as considerações do Estado Socioambiental de Direito como um Estado a garantir uma atuação de respeito, solidariedade, prudência e precaução do homem com a natureza, conforme destaca Armada (2015, p. 163).

Nesse sentido, impulsionando a sociedade para uma mudança de paradigma em dois níveis: no nível social, permitindo a consolidação da participação popular na decisão de assuntos de caráter ambiental; e, no nível ambiental, consolidando uma atuação mais solidária e sustentável. (ARMADA, 2015, p. 163)

Tudo só visa a sustentar ainda mais a defesa de que a construção teórica ideal seria de uma concepção de Sustentabilidade Solidária ou Solidariedade Sustentável. Tais categorias não estão só intimamente interligadas como apresentam-se dependentes, sendo que o resultado do seu entrelaçamento coaduna justamente com os critérios do socioambientalismo.

A verdade é que tanto a sustentabilidade como a solidariedade são fatos indissociáveis do socioambientalismo, que devera apresentar-se a partir da melhor equação de uma Sustentabilidade Solidária ou de uma Solidariedade Sustentável.

Peces Barba (1991, p. 55-57) já relembrava no despertar dos anos 90 que o valor da solidariedade é um motor para alcançar a liberdade igualitária e ao mesmo tempo uma das metas dessa liberdade igualitária, meta que a sua vez é moto para passos posteriores, sem que isso suponha aceitar uma perspectiva otimista enquanto a ideia de progresso.

A realidade que se impõe é a de que é impossível desvincular-se meio ambiente, vida humana - digna - e solidariedade. A sustentabilidade tem como foco a garantia dos dois primeiros. A solidariedade é meio indispensável para atingi-los. E o alcance do socioambientalismo é justamente garantir o equilíbrio pleno de todos esses elementos básicos.

\footnotetext{
${ }^{15}$ Destaca-se que utiliza-se neste momento a categoria desenvolvimento sustentável pois é a utilizada pela autora citada. A presente autora entende que desenvolvimento sustentável e sustentabilidade são conceitos divergentes, sendo aquele apenas um dos caminhos para se chegar a este, conforme entendimento consolidado por Gabriel Real Ferrer em: REAL FERRER, 2013.
} 


\section{CONSIDERAÇÕES FINAIS}

A Sustentabilidade numa visão geral, concatenando as ideias conceituais trabalhados no presente artigo, possui uma concepção acima de tudo ética, que trata de uma questão existencial, pois é algo que busca garantir a vida, não estando simplesmente relacionada à natureza, mas a toda uma relação entre indivíduo e todo o ambiente a sua volta. Sua abrangência é indiscutível e deve ser sempre considerada de caráter pluridimensional, comportando diversas dimensões diretamente interligadas de modo a proporcionar a visão da sustentabilidade como princípio-síntese que determina a proteção da própria vida humana na Terra.

Da mesma forma, a Solidariedade obrigatoriamente deverá contemplar um substrato ético, pois é valor fundamental para organização e harmonia das relações entre os seres humanos. Ela expressa valores contrários aos da economia clássica e ao liberalismo individualista, transmitindo valores do homem em comunidade, em relações de integração com os demais homens para realizar objetivos comuns e compartilhados, sendo, inclusive construída como garantida da dignidade da pessoa humana.

Nesse sentido, em consideração final ao estudo proposto, ressalta-se que a busca primordial do destino da espécie humana remanesce em suas próprias mãos, não podendo em nenhum momento haver a desvinculação das categorias Sustentabilidade e Solidariedade, razão pela qual defende-se a construção de um conceito uníssono entre ambas, seja de Sustentabilidade Solidária ou de Solidariedade Sustentável.

Temos de aceitar o caráter finito dos recursos naturais e a possibilidade de colocar em risco a continuação da humanidade por seu uso indiscriminado. Tem de se ter em mente a inclusão do outro no processo de proteção, e mais ainda, incluir aqueles que sequer estão aqui, as gerações futuras, aceitando o direito destas também usufruírem dos patrimônios culturais e ambientais.

\section{REFERÊNCIAS BIBLIOGRÁFICAS}

ARMADA, Charles Alexandre de Souza. O estado socioambiental de direito brasileiro e a concretização multidimensional da sustentabilidade. Revista Eletrônica Direito e Política, Itajaí, v. 10, n. 1, p. 157-174, edição especial de 2015. 
BECK, Ulrich. Sociedade de risco: rumo a uma outra modernidade. 2. ed. Trad. Sebastião Nascimento. São Paulo: Editora 34, 2011.

BEDLIN, Samara Loss; GARCIA, Denise Schmitt Siqueira. Dimensão social do princípio da sustentabilidade frente ao artigo $6^{\circ}$ da Constituição da República Federativa do Brasil de 1988. Revista Eletrônica Direito e Política. Itajaí, v. 6, n. 2, p. 419-441, $2^{\circ}$ quadrimestre de 2011.

BODNAR, Zenildo. Jurisdição ambiental para a solidariedade: desafios hermenêuticos. In: SOUZA, Maria Claudia da Silva Antunes; GARCIA, Heloise Siqueira (org.) Lineamentos sobre sustentabilidade segundo Gabriel Real Ferrer, - Dados eletrônicos. - Itajaí: UNIVALI, 2014. Disponível em: 〈www.univali.br/ppcj/ebooks〉. Acesso em: 18 de abril de 2016.

BOLSSELMANN, Klaus. O princípio da sustentabilidade: transformando direito e governança. Tradução de Phillip Gil França. São Paulo: RT, 2015.

BRANDÃO, Paulo de Tarso e SILVA, IIdete Regina Vale da. Fraternidade como categoria política. Revista Eletrônica Direito e Política, Programa de Pós-Graduação Stricto Sensu em Ciência Jurídica da UNIVALI, Itajaí, v.7, n.3, 3º quadrimestre de 2012.

BRASIL. Constituição da República Federativa do Brasil de 1988. Brasília, Poder Constituinte Originário, 1988.

CAMPANELLA, Tommaso. A cidade do Sol. São Paulo: Martin Claret, 2004.

CAMPELLO, Lívia Gaigher Bósio. Solidariedade e Cooperação Internacional na proteção do meio ambiente. In: SOUZA, Maria Claudia da Silva Antunes; GARCIA, Heloise Siqueira (org.) Lineamentos sobre sustentabilidade segundo Gabriel Real Ferrer - Dados eletrônicos. - Itajaí: UNIVALI, 2014. Disponível em: 〈www.univali.br/ppcj/ebooks〉. Acesso em: 18 de abril de 2016.

CARVALHO, Sônia Aparecida de. Justiça Social e Ambiental: um instrumento de consolidação à sustentabilidade. Revista Eletrônica Direito e Política. Itajaí, v. 9, n. 2, p. 755-779, $2^{\circ}$ quadrimestre de 2014 .

CRUZ, Paulo Márcio; BODNAR, Zenildo; participação especial Gabriel Real Ferrer. Globalização, transnacionalidade e sustentabilidade. Itajaí: UNIVALI, 2012. 
CRUZ, Paulo Márcio; REAL FERRER, Gabriel. Direito, Sustentabilidade e a Premissa Tecnológica como ampliação de seus Fundamentos. Sequência. Florianópolis, v. 36, n. 71, p. 239278, dez. 2015. Disponível em: <https://periodicos.ufsc.br/index.php/sequencia/article/view/21777055.2015v36n71p239>. Acesso em: 18 de abril de 2016.

FENSTERSEIFER, Tiago. Direitos fundamentais e proteção do ambiente: a dimensão ecológica da dignidade humana no marco jurídico constitucional do estado socioambiental de direito. Porto Alegre: Livraria do Advogado Editora, 2008.

FREITAS, Juarez. Sustentabilidade: direito ao futuro. 2. ed. Belo Horizonte: Fórum, 2012.

GARCIA, Denise Schmitt Siqueira. A atividade portuária como garantidora do Princípio da Sustentabilidade. Revista Direito Econômico Socioambiental, Curitiba, v. 3, n. 2, p. 375-399, jul./dez. 2012.

GARCIA, Denise Schmitt Siqueira; GARCIA, Heloise Siqueira. Dimensão social do princípio da sustentabilidade: uma análise do mínimo existencial ecológico. In: SOUZA, Maria Claudia da Silva Antunes; GARCIA, Heloise Siqueira (org.) Lineamentos sobre sustentabilidade segundo Gabriel Real Ferrer - Dados eletrônicos. - Itajaí: UNIVALI, 2014. Disponível em: <www.univali.br/ppcj/ebooks>. Acesso em: 18 de abril de 2016.

IRVING, Marta de Azevedo; OLIVEIRA, Elizabeth. Sustentabilidade e transformação social. Rio de Janeiro: Senac Nacional, 2012.

KELSEN, Hans. Teoria geral do direito e do Estado. 4. ed. Tradução de Luís Carlos Borges. São Paulo: Martins Fontes, 2005.

MALTHUS, Thomas. Ensaio sobre o princípio da população. Lisboa: Relogio D'agua, 2014.

MARTÍN MATEO, Ramón. Manual de derecho ambiental. 2. ed. Madrid: Editorial Trivium, 1998.

MILARÉ, Édis. Direito do Ambiente. 8. ed. São Paulo: RT, 2013.

MORUS, Thomas. A utopia. São Paulo: Saraiva de Bolso, 2011. 
PASOLD, Cesar Luis. Prática da Pesquisa Jurídica e metodologia da pesquisa jurídica. Florianópolis: OAB/SC Editora, 2007.

PECES BARBA, Gregorio. Humanitarismo y Solidaridad Social como valores de una sociedad avanzada. In: LORENZO GARCÍA, Rafael de (org.). Las entidades no lucrativas de carácter social y humanitario. Madrid: La Ley, 1991.

REAL FERRER, Gabriel. Calidad de vida, medio ambiente, sostenibilidad y ciudadanía ¿Construimos juntos el futuro? Revista Eletrônica Novos Estudos Jurídicos, ISSN Eletrônico 21750491, Itajaí, v. 17, n. 3, p. 310-326, dezembro de 2012. Disponível em: <http://siaiweb06.univali.br/seer/index.php/nej/article/view/4202>. Acesso em: 18 de abril de 2016.

REAL FERRER, Gabriel. La solidariedad en el derecho administrativo. Revista de Administración Pública (RAP), nº. 161, mayo-agosto 2003.

REAL FERRER, Gabriel. Sostenibilidad, Transnacionalidad y Trasformaciones del Derecho. In: SOUZA, Maria Cláudia da Silva Antunes de; GARCIA, Denise Schmitt Siqueira (orgs.) Direito ambiental, transnacionalidade e sustentabilidade. - Dados eletrônicos. - Itajaí: UNIVALI, 2013. Disponível em: <www.univali.br/ppcj/ebooks>. Acesso em 18 de abril de 2016.

REAL FERRER, Gabriel. La construcción del derecho ambiental. Revista Eletrônica Direito e Política, Itajaí, v.6, n.2, p. 472-505, agosto de 2011. Disponível em: <www.univali.br/direitoepolitica>. Acesso em: 18 de abril de 2016.

RIFKIN, Jeremy. La civilización empática. La carrera hacia una conciencia global en un mundo en crisis. Barcelona: Paidós, 2010.

SARLET, Ingo Wolfgang. As dimensões da dignidade da pessoa humana: construindo uma compreensão jurídico-constitucional necessária e possível. Revista Brasileira de Direito Constitucional - RBDC, n. 09, p. 361-388, jan/jun 2007.

SARLET, Ingo Wolfganf; FENSTERSEIFER, Tiago. Direito constitucional ambiental: constituição, direitos fundamentais e proteção do ambiente. 3. ed. São Paulo: RT, 2013. 
SILVA, José Afonso da. Comentário contextual à Constituição. 5. ed. São Paulo: Malheiros, 2008.

SMITH, Adam. A riqueza das nações. 4. ed. São Paulo: WMF Martins Fontes, 2016.

SOARES, Josemar; CRUZ, Paulo Márcio. Critério ético e sustentabilidade na sociedade pósmoderna: impactos nas dimensões econômicas, transnacionais e jurídicas. Revista Eletrônica Novos Estudos Jurídicos, Itajaí, v. 17, n. 3, p. 401-418, dezembro de 2012. Disponível em: <http://siaiweb06.univali.br/seer/index.php/nej/article/view/4208>. Acesso em 18 de abril de 2016.

VIEIRA, Ricardo Stanziola. Rio+20 - conferência das nações unidas sobre meio ambiente e desenvolvimento: contexto, principais temas e expectativas em relação ao novo "direito da sustentabilidade". Revista Eletrônica Novos Estudos Jurídicos, Itajaí, v. 17, n. 1, p. 48-69, abril de 2012. Disponível em: <http://siaiweb06.univali.br/seer/index.php/nej/article/view/3638>. Acesso em: 18 de abril de 2016. 